\title{
Photoreduction of carbon dioxide using strontium zirconate nanoparticles
}

\author{
Muhammad Naeem Ashiq ${ }^{1,2}$, Yanjie Wang ${ }^{1}$, Muhammad Fahad Ehsan ${ }^{1}$ and Tao $\mathrm{He}^{1^{*}}$
}

\begin{abstract}
The utilization of $\mathrm{CO}_{2}$ and solar energy have drawn much attention due to global warming and fuel crisis. Of particular interest in our research, we prepared strontium zirconate $\left(\mathrm{SrZrO}_{3}\right)$ nanoparticles as the photocatalyst to convert $\mathrm{CO}_{2}$ into value-added products. $\mathrm{SrZrO}_{3}$ nanoparticles were successfully synthesized via a sonochemical method and applied to the photoreduction of $\mathrm{CO}_{2}$. The samples were characterized by X-ray diffraction, Raman spectroscopy, scanning electron microscopy, Brunauere Emmette Teller measurement, $\mathrm{X}$-ray photoelectron spectroscopy and UV-vis absorption spectroscopy. Ethanol, methane and carbon monoxide were the major products with the yield respectively as follows, $41 \mu \mathrm{mol} \mathrm{g}^{-1}, 2.57 \mu \mathrm{mol} \mathrm{g}^{-1}$ and $1.6 \mu \mathrm{mol} \mathrm{g}{ }^{-1}$ after $4 \mathrm{~h}$ of reaction. The reason for the multiple photoreduction products is briefly discussed. Our work indicates that the as-prepared $\mathrm{SrZrO}_{3}$ nanoparticles can be used as a promising photocatalyst in turning $\mathrm{CO}_{2}$ into value-added chemicals.
\end{abstract}

\section{INTRODUCTION}

Scientists have been concerned about the energy and environmental issues, due to the limited amount of energy resources as well as the environmental issue caused by their combustion. They have been seeking for methods to take advantage of the renewable and clean energy sources such as sunlight. Moreover, fast growing carbon emission and its threat to the environment have led to the consensus that it is necessary to take efficient approaches to prevent the accumulation of $\mathrm{CO}_{2}[1,2]$. There are several ways to reduce the concentration of $\mathrm{CO}_{2}$ in the atmosphere, including removal [3], sequestration [4,5] and conversion [6,7]. A promising one is to capture $\mathrm{CO}_{2}$ from the atmosphere and convert it into higher energy compounds such as methane and methanol using sunlight $[8,9]$. By establishing this anthropogenic carbon cycle, one may simultaneously solve the issue of global warming as well as the sustainable energy shortage.

Inoue et al. [10] in 1979 have demonstrated the pho- tocatalytic reduction of $\mathrm{CO}_{2}$ into methanol, formic acid, methane and formaldehyde using semiconductor catalysts such as $\mathrm{TiO}_{2}, \mathrm{ZnO}, \mathrm{CdS}, \mathrm{GaP}$ and $\mathrm{WO}_{3}$. After that a variety of catalysts including metal oxides [11-13], sulfides $[14,15]$ and titanium-based materials [16-21] have been investigated for the efficient conversion of $\mathrm{CO}_{2}$ into either gas or liquid products. Recently, the peroveskite type materials $\mathrm{ABO}_{3}$ (such as $\mathrm{SrTiO}_{3}, \mathrm{BiVO}_{4}, \mathrm{SrZrO}_{3}$, etc.) have been drawn much attention for photocatalysis, due to their nontoxicity and stability [22,23]. Among them, $\mathrm{SrZrO}_{3}$ is an n-type perovskite semiconductor with a wide band gap, and it has been used as photocatalyst, proton-conductor material, high voltage and high reliability capacitor [24,25]. Recently, Tian et al. [26] synthesized $\mathrm{SrZrO}_{3}$ with a small amount of $\mathrm{MoS}_{2}$ loaded on the surface of $\mathrm{SrZrO}_{3}$ and applied the material as the photocatalyst for $\mathrm{H}_{2}$ evolution. The result indicated that $\mathrm{SrZrO}_{3}$ exhibited great potential in photocatalytic field. Because of its excellent stability and optical property, $\mathrm{SrZrO}_{3}$ can also be suitable for $\mathrm{CO}_{2}$ reduction under UV light irradiation, whereas there are scarcely ever studies on it.

In this paper, we synthesized $\mathrm{SrZrO}_{3}$ by a sonochemical method and reported the performance of photocatalytic conversion of dissolved $\mathrm{CO}_{2}$ in water under a $300 \mathrm{~W}$ Xenon lamp. The possible mechanism of the photoreduction of $\mathrm{CO}_{2}$ by $\mathrm{SrZrO}_{3}$ was also proposed.

\section{EXPERIMENTAL}

\section{Chemicals}

The chemicals used for the synthesis of $\mathrm{SrZrO}_{3}$ are $\mathrm{Sr}\left(\mathrm{NO}_{3}\right)_{2}$ (99.5\%), $\mathrm{ZrOCl}_{2} \cdot 8 \mathrm{H}_{2} \mathrm{O}$ (>99\%), cetyltrimethyl ammonium bromide (99\%), $\mathrm{KOH}$ (analytical grade $>82 \%$ ), $\mathrm{Pb}\left(\mathrm{NO}_{3}\right)_{2}(>99 \%)$ and thioacetamide $\left(\mathrm{C}_{2} \mathrm{H}_{5} \mathrm{NS}>99 \%\right)$. All the chemicals were purchased from Sinopharm Chemicals and were used as received without further treatment.

\footnotetext{
${ }^{1}$ CAS Key Laboratory of Nanosystem and Hierarchical Fabrication, National Center for Nanoscience and Technology, Beijing 100190, China

${ }^{2}$ Institute of Chemical Sciences, Bahauddin Zakariya University, Multan 60800, Pakistan

*Corresponding author (email: het@nanoctr.cn)
} 


\section{Synthesis of $\mathrm{SrZrO}_{3}$}

The $\mathrm{SrZrO}_{3}$ was synthesized by a sonochemical method using cetyltrimethyl ammonium bromide as the surfactant. The required concentrations of strontium and zirconium salts were dissolved in Milli-Q water. The metal to surfactant ratio was kept as 1:1.5 and $\mathrm{KOH}$ was used as precipitating agent. The mixture of solutions was kept in the sonicator for $2 \mathrm{~h}$. The precipitates were then washed with Milli-Q water for several times and then centrifuged. After that the precipitates were dried at $70^{\circ} \mathrm{C}$ in a vacuum oven and finally annealed at $650^{\circ} \mathrm{C}$ for $4 \mathrm{~h}$.

\section{Characterization of the photocatalyst}

The phase of the as-prepared $\mathrm{SrZrO}_{3}$ was confirmed by $\mathrm{X}$-ray diffraction (XRD) analysis using Bruker D8 focus diffractometer with $\mathrm{Ni}$-filtered $\mathrm{Cu}-\mathrm{Ka}$ radiation $(\lambda=$ $0.15406 \mathrm{~nm}$ ) and Raman spectroscopy with Renishaw Invia Raman microscope. A Lambda 750 UV/vis/NIR spectrophotometer (Perkin-Elmer, USA) was used to determine the optical properties. The valence band position was determined by X-ray photoelectron spectrometer (XPS) analysis with Thermo Scientific ESCALAB250 instrument using a monochromatized $\mathrm{Al} \mathrm{Ka}$ as the excitation source. Scanning electron microscopy (SEM) was carried out using Hitachi S4800 FE-SEM to study the surface morphology. The surface area, pore size and volume were determined by Brunauere Emmette Teller (BET) analysis (Micromeritics, tristar II 3020).

\section{Photocatalytic reduction of $\mathrm{CO}_{2}$}

The photocatalytic reaction was carried out in a Pyrex glass vessel, which was tightly closed during the reaction. $0.2 \mathrm{~g}$ $\mathrm{SrZrO}_{3}$ was dispersed into $200 \mathrm{~mL}$ of water. The $\mathrm{CO}_{2}$ was bubbled through the solution and the pressure was maintained at $30 \mathrm{kPa}$ throughout the reaction time. A $300 \mathrm{~W}$ PLS-SXE300C Xenon lamp was used as the light source. The products were detected with a gas chromatography/ liquid chromatography (GC/LC) system (Agilent Technologies, 7890A GC). For the detection of liquid products, 3 $\mathrm{mL}$ of the mixture was taken out by syringe every $30 \mathrm{~min}$. Then it was centrifuged and the resultant solution was run on LC system to characterize the liquid products.

\section{RESULTS AND DISSCUSION}

\section{Structure and composition analysis}

The XRD pattern of $\mathrm{SrZrO}_{3}$ is shown in Fig. 1. The sharpness of the peaks indicates that the obtained materials are crystalline in nature and the reflection peaks at $2 \theta=$ $30.2,34.9,50.3,59.7,62.7$ and $73.8^{\circ}$ correspond respec-

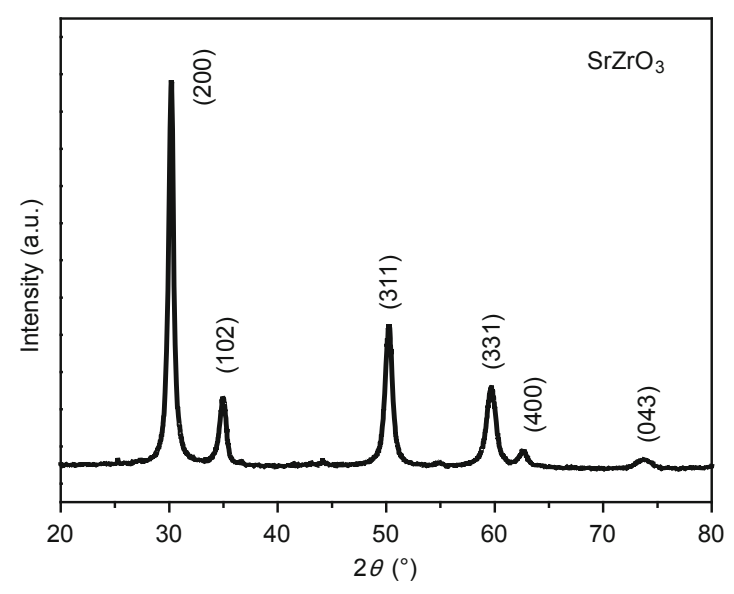

Figure 1 XRD pattern of $\mathrm{SrZrO}_{3}$.

tively to (200), (102), (311), (331), (400) and (430) planes (PDF\#44-0161), belonging to perovskite $\mathrm{SrZrO}_{3}$ phase with an orthorhombic structure. Moreover, no impurity can be observed in the as-synthesized material. According to the XRD data, the lattice parameters ( $a, b$ and $c$ ) are determined to be 5.818, 8.204 and $5.797 \AA$, respectively. The grain size $D$ is calculated using Scherrer's formula,

$$
D=0.89 \lambda / \beta \cos \theta,
$$

where $\lambda$ is the $\mathrm{X}$-ray wavelength, $\beta$ is the full width at half maximum of the peak, $\theta$ is the Bragg angle of the $\mathrm{X}$-ray diffraction. The average grain size is calculated using the X-ray reflections of the (200), (311) and (331) planes, which is found to be $16.1 \mathrm{~nm}$.

The Raman spectrum has been used to further confirm the formation of $\mathrm{SrZrO}_{3}$ (Fig. 2). The peaks at 144, 165, 266, $319,409,457,556$ and $635 \mathrm{~cm}^{-1}$ are observed in the Raman

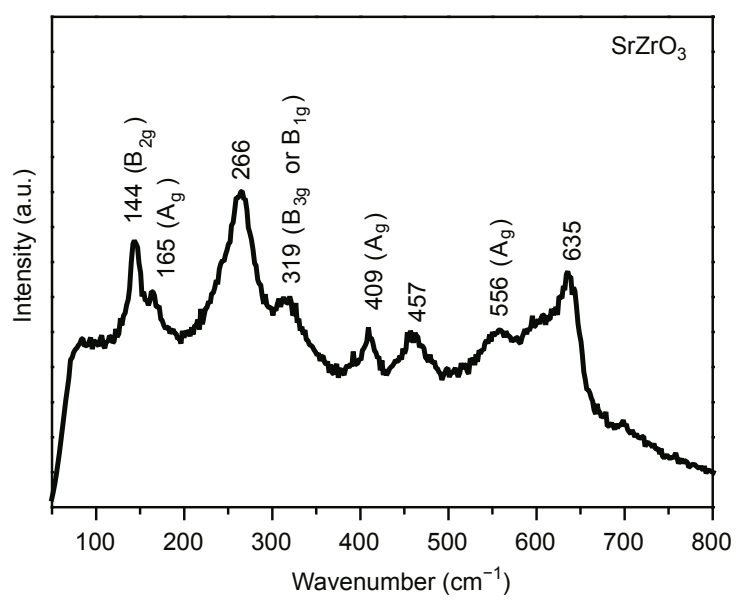

Figure 2 Raman spectrum of the as-prepared $\mathrm{SrZrO}_{3}$. 
spectrum of the zirconate. All these peaks correspond to $\mathrm{SrZrO}_{3}$, confirming the orthorhombic phase of the material, which is in good agreement with the XRD result. The peaks at 165,409 and $556 \mathrm{~cm}^{-1}$ are attributed to the $A_{g}$ mode of $\mathrm{SrZrO}_{3}$, while the one at $144 \mathrm{~cm}^{-1}$ corresponds to the $\mathrm{B}_{2 \mathrm{~g}}$ mode [27]. The band at $266 \mathrm{~cm}^{-1}$ corresponds to the $\mathrm{Zr}-\mathrm{O}$ bending mode and the one at $319 \mathrm{~cm}^{-1}$ is related to the $\mathrm{B}_{1 \mathrm{~g}}$ or $\mathrm{B}_{3 \mathrm{~g}}$ mode. The band at $457 \mathrm{~cm}^{-1}$ corresponds to the $\mathrm{Zr}-\mathrm{O}$ stretching vibration mode of $\mathrm{SrZrO}_{3}$. The band at $635 \mathrm{~cm}^{-1}$ is ascribed to the second order scattering feature, resulting from the superposition of various combination modes [28].

\section{Morphology characteristic}

The SEM image of the $\mathrm{SrZrO}_{3}$ is shown in Fig. 3. The particles are in spherical shape and some of them are aggregated. The particle size is found to be in the range of 15-25 nm, a little bit larger than the grain size calculated from XRD, which is reasonable. The BET specific surface area of the obtained materials is determined on the basis of nitrogen adsorption-desorption measurements. The surface area, pore volume and pore size of $\mathrm{SrZrO}_{3}$ are respectively $36.53 \mathrm{~m}^{2} \mathrm{~g}^{-1}, 0.086 \mathrm{~cm}^{3} \mathrm{~g}^{-1}$ and $8.70 \mathrm{~nm}$, implying that the material is porous, beneficial for the adsorption of $\mathrm{CO}_{2}$.

\section{Photocatalytic properties}

The obtained $\mathrm{SrZrO}_{3}$ is used to photoreduce $\mathrm{CO}_{2}$ and the products observed are shown in Fig. 4. The major products observed in the gas phase are methane and carbon monoxide, and it is ethanol in the liquid phase. Fig. 4 shows the effect of irradiation time on the formation of ethanol, methane and carbon monoxide during the photoreduction of $\mathrm{CO}_{2}$. It is found that the yields of ethanol, methane and carbon monoxide after $4 \mathrm{~h}$ are $41,2.57$ and $1.6 \mu \mathrm{mol} \mathrm{g}^{-1}$, re-

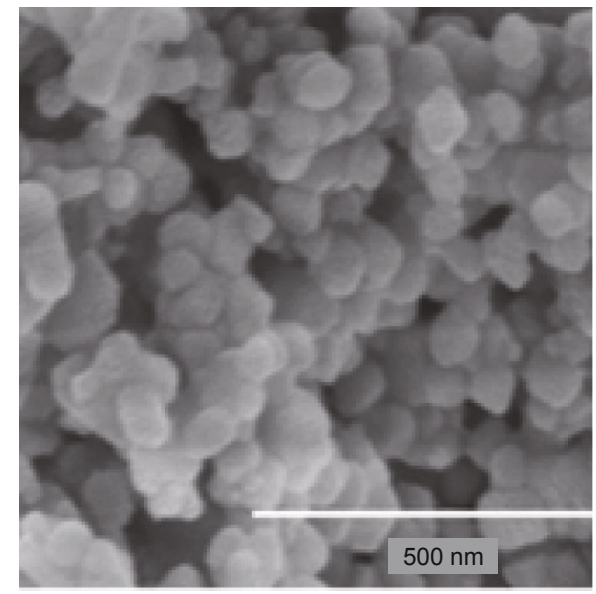

Figure $3 \mathrm{SEM}$ image of $\mathrm{SrZrO}_{3}$.

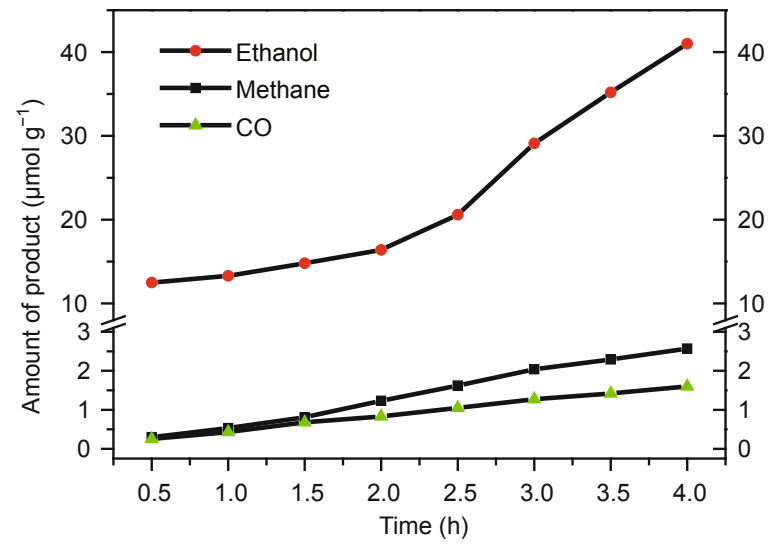

Figure 4 Photocatalytic evolution of ethanol, methane and carbon monoxide by using $\mathrm{SrZrO}_{3}$.

spectively. To confirm the observed products were indeed due to the photoreduction of $\mathrm{CO}_{2}$ over the obtained photocatalyst, four control experiments were carried out, i.e., blank reactor with and without irradiation, under the same experimental conditions but using $\mathrm{N}_{2}$ instead of $\mathrm{CO}_{2}$, and dark experiment with the photocatalyst. No products were observed in these control experiments. Thus, the observed products are from the photocatalytic reduction of $\mathrm{CO}_{2}$.

\section{Mechanism analysis}

Fig. 5 shows the UV/vis absorption spectra of $\mathrm{SrZrO}_{3}$. The band gap of the semiconductor can be calculated by the Tauc plot, as shown in the inset of Fig. 5. Thus, the band gap is determined to be $5.35 \mathrm{eV}$ for $\mathrm{SrZrO}_{3}$. Such a high value can be explained on the basis of the small crystallite size as calculated by XRD and band structure of $\mathrm{SrZrO}_{3}$. The minimum conduction band of $\mathrm{SrZrO}_{3}$ mainly consists of $\mathrm{Zr} 4 \mathrm{~d}, \mathrm{Sr} 4 \mathrm{~d}$ and $\mathrm{O} 2 \mathrm{p}$ empty orbitals, while the valence

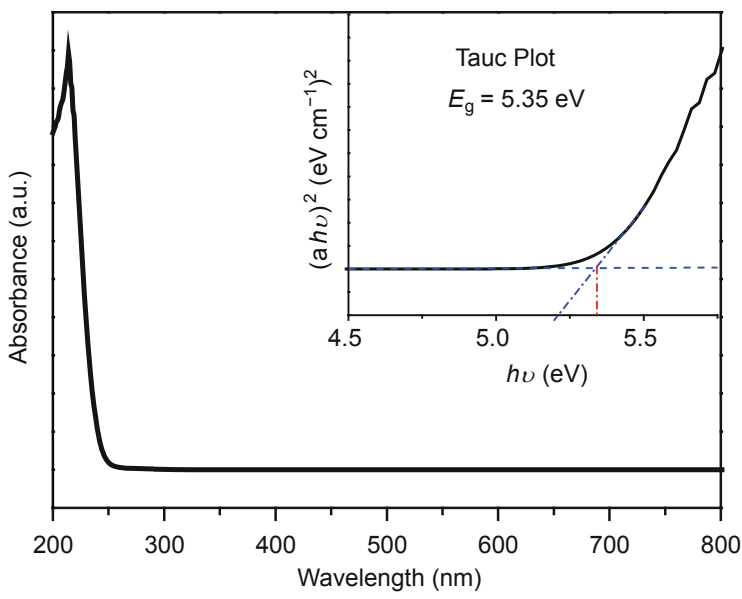

Figure $5 \mathrm{UV} /$ vis spectra of $\mathrm{SrZrO}_{3}$. 
band maximum is mainly composed of $\mathrm{O} 2 \mathrm{p}$ atomic orbital [29]. It has been reported that the small grain size results in the increase in lattice parameters that can cause weak hybridization between $\mathrm{Zr} 4 \mathrm{~d}$ and $\mathrm{O} 2 \mathrm{p}$ states. This can directly lower the top of valence band and raise the bottom of conduction band, which is responsible for the high band gap value [30].

The position of the valence band maximum was determined by XPS valence band spectrum (Fig. 6), which is $2.1 \mathrm{eV}$ for $\mathrm{SrZrO}_{3}$. The work function for the XPS instrument is $4.62 \mathrm{eV}$. Therefore, the valence band position for $\mathrm{SrZrO}_{3}$ is $6.72 \mathrm{eV} v s$. vacuum and $2.22 \mathrm{~V} v s$. NHE, provided that $4.5 \mathrm{eV} v s$. vacuum energy level equals $0 \mathrm{~V} v s$. NHE. Accordingly, the conduction band for $\mathrm{SrZrO}_{3}$ is $1.37 \mathrm{eV} v$. vacuum and $-3.13 \mathrm{~V} v s$. NHE. Thus, the energy levels of $\mathrm{SrZrO}_{3}$ and the relevant redox potentials for $\mathrm{CO}_{2}$, are presented in Fig. 7.

Hence, the photocatalytic activity of the material in this work can be elucidated in the light of Fig. 7. Thermody-

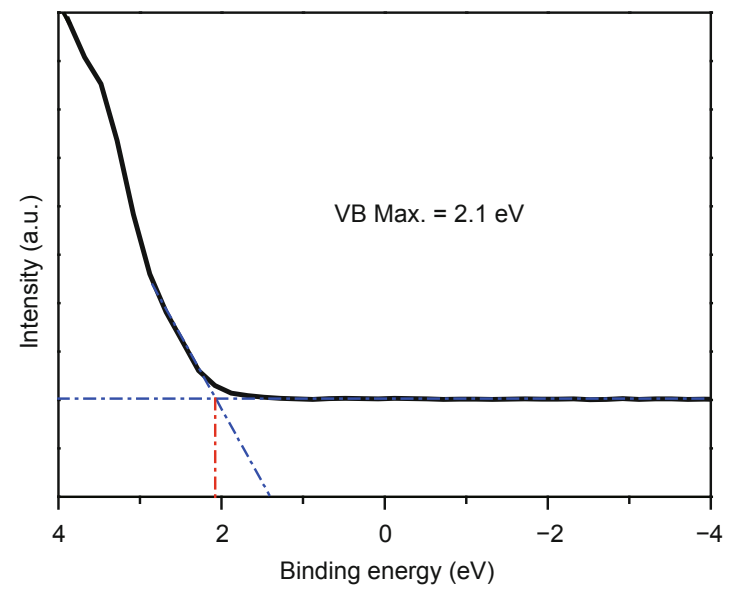

Figure 6 XPS valence band spectrum of $\mathrm{SrZrO}_{3}$.

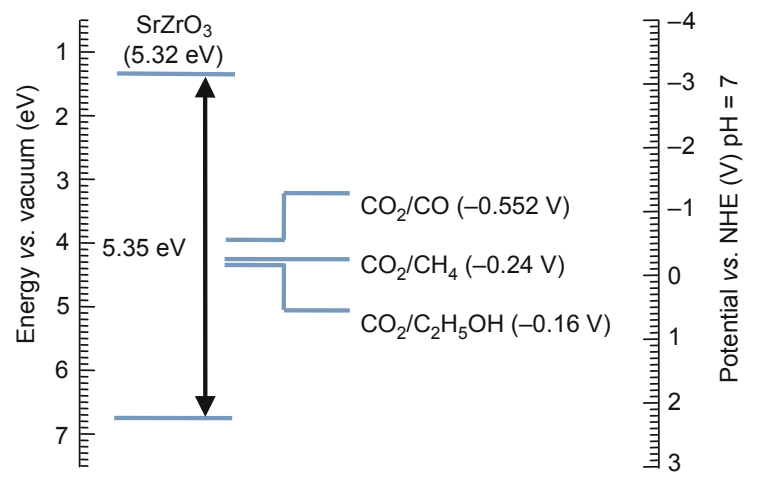

Figure 7 Band edge positions of $\mathrm{SrZrO}_{3}$ with relevant redox potentials of $\mathrm{CO}_{2}$. namically, the product with redox potential within the band gap is possible. It can be seen from Fig. 7 that the conduction band of $\mathrm{SrZrO}_{3}$ lies above the redox potential of methane, ethanol and carbon monoxide, indicating that all of them are possible products of the reduction of $\mathrm{CO}_{2}$ by $\mathrm{SrZrO}_{3}$. Upon irradiation, the energy of the photo-generated electrons is high enough due to the negative conduction band level of $\mathrm{SrZrO}_{3}$. The first step is the activation of $\mathrm{CO}_{2}$ on the catalyst surface to form the superoxide $\left(\cdot \mathrm{CO}_{2}^{-}\right)$radicals [31-33]. The photo-generated electrons can react with the $\mathrm{H}^{+}$ions in the solution to produce $\cdot \mathrm{H}$ radicals that can react with the $\cdot \mathrm{CO}_{2}{ }^{-}$radicals to form $\mathrm{CO}$. The resultant $\mathrm{CO}$ can also be converted into $\mathrm{C}$ radicals, followed by the formation of a series of $\cdot \mathrm{CH}, \cdot \mathrm{CH}_{2}$ and $\cdot \mathrm{CH}_{3}$ radicals through successive reactions [33], which can react with $\mathrm{H}_{2} \mathrm{O}, \mathrm{H}^{+}$or - $\mathrm{OH}$ to produce methane or ethanol. Meanwhile, the photo-generated holes may oxidize the water as well as other possible reduction products like $\mathrm{HCOOH}, \mathrm{HCHO}$ and $\mathrm{CH}_{3} \mathrm{OH}$, as they were not observed in the products. The reason that the yield of ethanol is much higher than that of $\mathrm{CO}$ and methane is not very clear hitherto. In addition, the kinetic challenges should be considered since the formation reactions for all of the possible products are those of multi-protons coupled with multi-electrons. Nevertheless, all these need further study.

Our work has proved that $\mathrm{SrZrO}_{3}$ is a potential material for $\mathrm{CO}_{2}$ photoreduction. But it cannot utilize the solar spectrum efficiently, as it is only responsive to the UV light due to its very large band gap, which makes up only $4 \%$ of the entire solar spectrum. To use $\mathrm{SrZrO}_{3}$ under visible light that covers almost $43 \%$ of the solar spectrum, it needs to be decorated by other semiconductor with narrow band gap to form a heterojunction. In this case, the alignment of electronic energy levels at the heterointerface between the two materials could facilitate the electron-hole separation, charge transfer and decrease the electron-hole recombination possibility.

\section{CONCLUSION}

In summary, sonochemical synthesized $\mathrm{SrZrO}_{3}$ was used as the photocatalyst for $\mathrm{CO}_{2}$ reduction. The reduction products are ethanol, methane and carbon monoxide with the yield after $4 \mathrm{~h}$ are $41,2.57$ and $1.6 \mu \mathrm{mol} \mathrm{g}{ }^{-1}$, respectively. The reaction mechanism was briefly discussed. Our work indicates that $\mathrm{SrZrO}_{3}$ could be a good material in effectively converting $\mathrm{CO}_{2}$ into value-added products.

Received 28 July 2015; accepted 11 August 2015; published online 19 August 2015

1 Maginn EJ. What to do with $\mathrm{CO}_{2}$. J Phys Chem Lett, 2010, 1: 34783479 
2 Mikkelsen M, Jorgensen M, Krebs FC. The teraton challenge: a review of fixation and transformation of carbon dioxide. Energy Environ Sci, 2010, 3: 43-81

3 Yeh AC, Bai H. Comparison of ammonia and monoethanolamine solvents to reduce $\mathrm{CO}_{2}$ greenhouse gas emissions. Sci Total Environ, 1999, 228: 121-133

4 Lackner Klaus. Climate change: a guide to $\mathrm{CO}_{2}$ sequestration. Science, 2003, 300: 1677-1678

5 Bachu S. Sequestration of $\mathrm{CO}_{2}$ in geological media: criteria and approach for site selection in response to climate change. Energy Convers Manage, 2000, 41: 953-970

6 He Y, Wang Y, Zhang L, Teng B, Fan M. High-efficiency conversion of $\mathrm{CO}_{2}$ to fuel over $\mathrm{ZnO} / \mathrm{g}-\mathrm{C}_{3} \mathrm{~N}_{4}$ photocatalyst. Appl Catal B Environ, 2015, 168: 1-8

7 Richter RK, Ming T, Caillol S. Fighting global warming by photocatalytic reduction of $\mathrm{CO}_{2}$ using giant photocatalytic reactors. $\mathrm{Re}$ new Sust Energ Rev, 2013, 19: 82-106

8 Yuan L, Xu YJ. Photocatalytic conversion of $\mathrm{CO}_{2}$ into value-added and renewable fuels. Appl Surf Sci, 2015, 342: 154-167

9 Li X, Wen JQ, Low JX, Fang YP, Yu JG. Design and fabrication of semiconductor photocatalyst for photocatalytic reduction of $\mathrm{CO}_{2}$ to solar fuel. Sci Chin Mater, 2014, 57: 70-100

10 Inoue T, Fujishima A, Konishi S, Honda K. Photoelectrocatalytic reduction of carbon dioxide in aqueous suspensions of semiconductor powders. Nature, 1979, 277: 637-638

11 Albo J, Saez A, Solla-Gullón J, Montielb V, Irabien A. Production of methanol from $\mathrm{CO}_{2}$ electroreduction at $\mathrm{Cu}_{2} \mathrm{O}$ and $\mathrm{Cu}_{2} \mathrm{O}-\mathrm{ZnO}$ based electrodes in aqueous solution. Appl Catal B Environ, 2015, 176: 709-717

12 Yin G, Nishikawa M, Nosaka Y, et al. Photocatalytic carbon dioxide reduction by copper oxide nanocluster-grafted niobate nanosheets. ACS Nano, 2015, 9: 2111-2119

13 Wang YG, Wang F, Chen YT, et al. Enhanced photocatalytic performance of ordered mesoporous $\mathrm{Fe}$-doped $\mathrm{CeO}_{2}$ catalysts for the reduction of $\mathrm{CO}_{2}$ with $\mathrm{H}_{2} \mathrm{O}$ under simulated solar irradiation. Appl Catal B Environ, 2014, 147: 602-609

14 Arai T, Tajima S, Sato S, et al. Selective $\mathrm{CO}_{2}$ conversion to formate in water using a CZTS photocathode modified with a ruthenium complex polymer. Chem Commun, 2011, 47: 12664-12666

15 Chen J, Qin S, Song G, et al. Shape-controlled solvothermal synthesis of $\mathrm{Bi}_{2} \mathrm{~S}_{3}$ for photocatalytic reduction of $\mathrm{CO}_{2}$ to methyl formate in methanol. Dalton Trans, 2013, 42: 15133-15138

16 Akhter P, Hussain M, Saracco G, Russo N. Novel nanostructured- $\mathrm{TiO}_{2}$ materials for the photocatalytic reduction of $\mathrm{CO}_{2}$ greenhouse gas to hydrocarbons and syngas. Fuel, 2015, 149: 55-65

$17 \mathrm{Xu}$ Q, Yu J, Zhang J, Zhang J, Liu G. Cubic anatase $\mathrm{TiO}_{2}$ nanocrystals with enhanced photocatalytic $\mathrm{CO}_{2}$ reduction activity. Chem Commun, 2015, 51: 7950-7953

18 Yu JG, Low JX, Xiao W, Zhou P, Jaroniec M. Enhanced photocatalytic $\mathrm{CO}_{2}$-reduction activity of anatase $\mathrm{TiO}_{2}$ by coexposed $\{001\}$ and \{101\} facets. J Am Chem Soc, 2014, 136: 8839-8842

19 Hussain M, Akhter P, Saracco G, Russo N. Nanostructured $\mathrm{TiO}_{2} /$ KIT-6 catalysts for improved photocatalytic reduction of $\mathrm{CO}_{2}$ to tunable energy products. Appl Catal B Environ, 2015, 170/171: 53-65
20 Li QY, Zong LL, Li C, Yang JJ. Photocatalytic reduction of $\mathrm{CO}_{2}$ on $\mathrm{MgO} / \mathrm{TiO}_{2}$ nanotube films. Appl Surf Sci, 2014, 314: 458-463

21 Rani S, Bao NZ, Roy SC. Solar spectrum photocatalytic conversion of $\mathrm{CO}_{2}$ and water vapor into hydrocarbons using $\mathrm{TiO}_{2}$ nanoparticle membranes. Appl Surf Sci, 2014, 289: 203-208

22 Wang Q, Hisatomi T, Ma SSK, Li Y, Domen K. Core/shell structured La- and Rh-codoped $\mathrm{SrTiO}_{3}$ as a hydrogen evolution photocatalyst in $Z$-scheme overall water splitting under visible light irradiation. Chem Mat, 2014, 26: 4144-4150

23 Soma K, Iwase A, Kudo A. Enhanced activity of $\mathrm{BiVO}_{4}$ powdered photocatalyst under visible light irradiation by preparing microwave-assisted aqueous solution methods. Catal Lett, 2014, 144: 1962-1967

24 Guo Z, Sa B, Pathak B, et al. Band gap engineering in huge-gap semiconductor $\mathrm{SrZrO}_{3}$ for visible-light photocatalysis. Int J Hydrogen Energ, 2014, 39: 2042-2048

25 Lai C, Liu C. Direct current voltage sweep and alternating current impedance analysis of $\mathrm{SrZrO}_{3}$ memory device in $\mathrm{ON}$ and OFF states. 2013, 103: 263505

26 Tian Q, Zhang L, Liu J, at al. Synthesis of $\mathrm{MoS}_{2} / \mathrm{SrZrO}_{3}$ heterostructures and their photocatalytic $\mathrm{H}_{2}$ evolution under UV irradiation. Rsc Adv, 2015, 5: 734-739

27 Kamishima O, Hattori T, Ohta K, Chiba Y, Ishigame M. Raman scattering of single-crystal $\mathrm{SrZrO}_{3}$. J Phys Condens Matter, 1999, 11: 5355-5365

28 Tarrida M, Larguem H, Madon M. Structural investigations of $(\mathrm{Ca}, \mathrm{Sr}) \mathrm{ZrO}_{3}$ and $\mathrm{Ca}(\mathrm{Sn}, \mathrm{Zr}) \mathrm{O}_{3}$ perovskite compounds. Phys Chem Minerals, 2009, 36: 403-413

29 Zhang A, Lu M, Wang S, et al. Novel photoluminescence of $\mathrm{SrZrO}_{3}$ nanocrystals synthesized through a facile combustion method. J Alloys Compd, 2007, 433: L7-L11

30 Cohen RE. Origin of ferroelectricity in perovskite oxides. Nature, 1992, 358: 136-138

31 Inrakanti VP, Kubicki JD, Schobert HH. Photoinduced activation of $\mathrm{CO}_{2}$ on Ti-based heterogeneous catalysts: current state, chemical physics-based insights and outlook. Energy Environ Sci, 2009, 2: 745-758

32 Shkrob IA, Marin TW, He HY, Zapol P. Photoinduced activation of $\mathrm{CO}_{2}$ on Ti-based heterogeneous catalysts: current state, chemical physics-based insights and outlook. J Phys Chem C, 2012, 116: 9450-9460

33 Koci K, Obalova L, Matejova L, et al. Effect of $\mathrm{TiO}_{2}$ particle size on the photocatalytic reduction of $\mathrm{CO}_{2}$. Appl Catal B, 2009, 89: 494-502

Acknowledgements This work was supported by the Ministry of Science and Technology of China (2015DFG62610). Ashiq MN is highly thankful to Higher Education Commission (HEC) of Pakistan for the financial support under Post-Doctoral fellowship program.

Author contributions Muhammad NA and Muhammad FE designed and performed the experiments; Wang Y and Muhammad NA analyzed the results and wrote the manuscript; He T supervised the project and revised the manuscript. All authors contributed to the general discussion.

Conflict of interest The authors declare that they have no conflict of interest. 


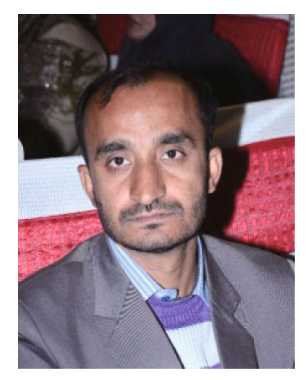

Muhammad Naeem Ashiq was born in 1979. He received his PhD degree in chemistry from the Department of Chemistry, Quaid-i-azam University, Islamabad, Pakistan in 2009, and then he became a postdoctor in the National Center for Nanoscience and Technology, Beijing, China in 2012. Currently, He is an assistant professor in the Institute of Chemical Sciences Bahauddin Zakariya University, Multan, Pakistan. His research interests include photocatalysis, magnetic nanomaterials and nanocomposites.

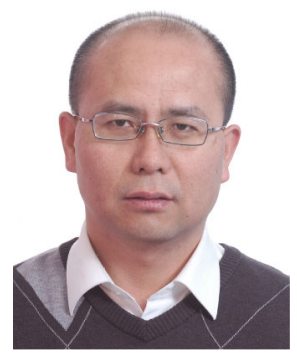

Tao He was born in 1971. He received his PhD degree in chemistry from the Institute of Chemistry, Chinese Academy of Sciences, Beijing, China in 2002, and was a postdoctor in Weizmann Institute of Science and Rice University from 2002 to 2009. Currently, He is a professor in the National Center for Nanoscience and Technology, Beijing, China. His research interests include controllable synthesis of nanomaterials and catalytic reduction of $\mathrm{CO}_{2}$ into value-added chemicals using nanocatalysts.

中文摘要 全球变暖和能源危机使得人们开始同时关注二氧化碳和太阳能的利用. 在本工作中, 我们制备了 $\mathrm{SrZrO}_{3}$ 纳米颗粒, 并将其 作为催化剂使二氧化碳转化为高能量附加值产品. 我们利用超声化学法成功制备了 $\mathrm{SrZrO}_{3}$ 纳米材料, 并通过X射线衍射(XRD)、拉曼光 谱、扫描电子显微镜(SEM)、BET比表面积分析、X射线光电子能谱(XPS)以及紫外-可见吸收光谱(UV/vis)等对样品进行了相应表征. 将 $\mathrm{SrZrO}_{3}$ 作为催化剂, 在 $300 \mathrm{~W}$ 氙灯光源照射下进行光催化还原二氧化碳实验, 结果表明乙醇、甲烷和一氧化碳是主要的光催化产物, 反应进行 4 小时后, 三种产物相应的产量分别为 $41 、 2.57$ 和 $1.6 \mu \mathrm{mol} \mathrm{g}{ }^{-1}$. 论文分析了三种产物生成的原因. 本研究工作表明, $\mathrm{SrZrO}_{3}$ 纳米 材料可以作为一种有效的催化剂应用于光催化还原二氧化碳. 